\title{
NOTAS
}

\section{LOS DESEOS DE TOMÁS Y MARCELA}

Porque donde esté vuestro tesoro,
allí estará también vuestro corazón.

MATEO 6:21

El tema del rechazo al amor es una constante cervantina, está presente en La Galatea, el Quijote y las Novelas ejemplares. El rechazo al amor de don Quijote ha sido estudiado ampliamente aunque, para desconcierto de críticos optimistas como yo, no de modo exhaustivo. Tales aguas profundas deseo evitar por ahora. En este ensayo quiero fijar mi atención en dos personajes que, además de tener algo de quijotescos ${ }^{1}$, son conocidos principalmente por su rechazo al amor.

Para entender la psicología de un personaje hay que preguntarse cuáles son sus motivaciones. Para ello, en este ensayo me serviré de la formulación, establecida por Slavoj Zizek, "che vuoi?”, que resume la esencia de la cita bíblica que encabeza mi trabajo (Mateo 6:21). Sin entrar en consideraciones teóricas intrincadas ${ }^{2}$, retomaré la pregunta formulada por Zizek (“¿qué quieren?”) y la dirigiré a dos personajes cervantinos, para tratar de entender no sólo lo que quieren sino cómo es eso que quieren: ¿qué desean, pues, la pastora Marcela y el licen-

\footnotetext{
${ }^{1}$ Para Marcela, véase Carroll B. Johnson, Madness and lust: A psychoanalytical approach to Don Quixote, University of California Press, Berkeley, 1983. La semejanza con el licenciado Vidriera, por ser más explícita, ha sido más advertida (por ejemplo, JoHN G. WeIGER, The individuated self: Cervantes and the emergence of the individual, Ohio University Press, Athens, 1979). Llamo la atención sobre el hecho de que estas dos novelitas sirven como recreación o variante de un tema que, si bien no es el principal en la obra maestra cervantina, parece que inquietó mucho a nuestro autor.

2 Slavoj Zizer desarrolla el tema del "sublime objeto del deseo" mediante una lectura lacaniana de los textos. A través de la mirada se puede comprender, según Zizek, la ideología (económica, religiosa, sexual) de un personaje. Evito el tipo de escritura lacaniana en este ensayo, pero trato en la medida de lo posible de ajustarme a los paradigmas de Zizek (El sublime objeto de la ideología, trad. I. Vericat Núñez, Siglo Veintiuno, México, 1992).
}

NRFH, LV (2007), núm. 1, 141-151 
ciado Vidriera? Parecería que, para ambos personajes, el amor es un obstáculo que les impide alcanzar aquello que anhelan.

Los respectivos rechazos al amor entre ambos personajes varían. Mientras Vidriera enloquece de un modo particular, Marcela decide vivir en un ámbito literario y fantasioso (un mundo que, por ser enajenado, no existe $)^{3}$. S. Hutchinson afirma, en un interesante trabajo dedicado al deseo como motor de los personajes cervantinos de las Novelas ejemplares, que el deseo tiene, casi siempre, origen económico. Aunque no se refiere de manera directa al licenciado Vidriera, opina sobre el tema de los deseos que, aunque "most of them are amorous (in the novels) ... they operate in every other domain of wanting as well, including the commonly stated desire to know... characters live by desire and sometimes die because of it too... In Cervantes's novels, desires above all move and motivate"

En El licenciado Vidriera, el episodio del envenenamiento de Tomás es crucial en la novela, y entiendo que debe tener primacía en el estudio de su historia. Maurice Molho nos ha regalado valiosas pistas para comprenderla; una de ellas es la idea, que prueba, de que la poción mágica no es la causa de la locura del personaje, sino el simbólico membrillo (sexo femenino metafórico que le han insertado por fuerza) ${ }^{5}$; una más es aquella que alude al cuerpo de vidrio del personaje, "un cuerpo que es lo menos cuerpo posible: una transparencia de cuerpo que, según pretende, no obstaculiza el entendimiento"6. Otra idea sugestiva que propone Molho -y con la cual difiero, como explicaré a continuación- es que el personaje es un viajero tópico que sólo recorre lugares comunes. Sorprende una conclusión increíblemente desatinada a un ensayo tan ingenioso y elegante: la problemática de Vidriera se explica por una homosexualidad solapada; la evidencia textual que propone el crítico para sostener esta idea es, por supuesto, inexistente. Creo que el desacierto consiste en la búsqueda de un origen infantil del trauma. Aunque por instantes parece haberlo

\footnotetext{
${ }^{3}$ Citaré ambos casos por Miguel de Cervantes SaAvedra, "El licenciado Vidriera", Novelas ejemplares, t. 2, ed. H. Sieber, Cátedra, Madrid, 2000 y Don Quijote de la Mancha, Primera parte, ed. J. Jay Allen, Cátedra, Madrid, 1996, indicando número de página entre paréntesis.

${ }^{4}$ S. Hutchinson, "Desire mobilized in Cervantes's novels", JHPh, 16 (1990), núm. 2, p. 163 .

${ }^{5}$ Tomás, por supuesto, enloquece por culpa del veneno, no por obra de la magia (como indica MaUrice MolHo), pero tampoco por ninguna razón psicológica (como también propone el crítico). Con todo, sigo el hilo argumental de Molho, ya que hay indicios en el texto (en relación con el resto de la obra cervantina) que nos indican que hay más que sólo veneno en el envenenamiento de Tomás. Además, afirmando lo opuesto, corremos el riesgo de ser poco exhaustivos (véase "Una dama de todo rumbo y manejo. Para una lectura de El licenciado Vidriera", en Erotismo en las letras hispánicas: aspectos, modos y fronteras, eds. L. López-Baralt y F. Márquez Villanueva, El Colegio de México, México, 1995, pp. 387-406).

${ }^{6}$ M. MolHo, art. cit., pp. 392-393.
} 
considerado, Molho desdeña el deseo del personaje y llena los espacios vacíos del texto con una historia de su propia factura, que intenta desentrañar una conciencia de sexualidad atormentada, obviando la validez del deseo de Tomás por sí mismo, éste no es el caso.

El personaje, que se hace llamar a sí mismo "Tomás Rodaja", quiere estudiar para honrar a sus padres y su patria, esa es la razón por la que "duerme en soledad". Él mismo afirma que servirá a un amo "por sólo que le diese estudio" (p. 43), esto es lo que quiere. La peripecia narrada en la novela es producto de la lucha del personaje por obtener lo que desea: la fama por medio del conocimiento. Así, el ofrecimiento hecho por el capitán Valdivia, o la seducción que éste ejerce sobre Tomás, es conocimiento cultural de primera mano. Si bien la idea de "cultura" en el siglo XVII no corresponde a la nuestra -y la tradición del grand tour es algo posterior-, parece indudable que el viaje era parte del conocimiento (y formación) del hombre renacentista. Desconcierta un tanto, no obstante, que la economía y la matemática formaran parte de esta programación. Tomás piensa que "podía gastar tres o cuatro años, que añadidos a los pocos que él tenía, no serían tantos que le impidiesen volver a sus estudios" (p. 46); el viaje parece tópico por lo programado y por lo sucinto de su descripción.

Tomás quiere tener las cuentas claras y no desviarse de su propósito; por eso rechaza la oferta de Valdivia de vivir a costa del ejército (p. 46). También es interesante que, entre las cosas hermosas y sorprendentes que observa, "note" sobre todo el maltrato, la destrucción y las fatigas de la gente, y las asocie a las distintas profesiones de cada uno de ellos (p. 47). No hay por qué concebir a Tomás como un conjunto de virtudes ${ }^{7}$, desde luego, pero lo cierto es que es un joven aplicado y dedicado a su meta. Este punto es muy importante: Tomás tiene muy claro su objetivo y se encamina hacia él sin descarriarse o entretenerse.

Lo que Tomás aprende en su viaje se presenta a manera de catálogo, ya sean las costumbres de las personas que encuentra como los lugares que visita. No creo necesario afirmar, como lo hace Molho, que Tomás es un turista tópico; el relato de Cervantes no tiene por qué ser un texto de viajes ortodoxo. Para los propósitos de la narración, la velocidad es suficiente ${ }^{8}$. Tomás viaja para ver, una vez que ve, deja de viajar ${ }^{9}$. El viaje sirve a su función, sin necesidad de adquirir protagonismo. Sybil Dümchen apunta al respecto que:

${ }^{7}$ Como hace Stanislav Zimic, en una especie de panegírico que escribe a su nombre ("El licenciado Vidriera: la tragedia del intelectual íntegro", LT, 1992, núm. 22, 237-270).

${ }^{8}$ Entiendo que, aunque Cervantes es un autor con conciencia de estilo (si ha habido alguno), resulta demasiado exigente pedirle que ajuste cada partícula textual a una narración pormenorizada. El asunto, en todo caso, se desarrolla del modo en que lo leemos. Además, del mismo modo hace Guevara en El diablo cojuelo.

9 "Habiendo cumplido con el deseo que le movió a ver lo que había visto, determinó volverse a España y a Salamanca a acabar sus estudios" (p. 51). 
Discreto, then, can hardly be applied to the Licenciado, because he travels without benefit to himself. He tries to exist, negating his biological and social background; he neither thinks in a harmonic, holistic way nor does he assign an adequate position to each element. He ignores important aspects of life. He always judges others and never speaks about himself. In Cervantes's way of thinking, this can only lead to madness and death ${ }^{10}$.

Aunque estoy de acuerdo con Dümchen en otros aspectos, no lo estoy en lo que se refiere al juicio valorativo que hace del viaje, con respecto al personaje, partiendo de un final que considera infeliz. La narración del viaje por Italia, dice, "shows in an impressive way how Vidriera experiences the outside world, by superficial looking/watching without any effects upon his inner world"11. Al igual que Molho, olvida que el aprendizaje apresurado, inmediato y hambriento de Tomás es precisamente lo que desea éste. El éxito del personaje muy bien podría consistir en lograr hacer lo que desea.

Hasta ahora hemos visto que Tomás lleva una vida productiva con la cual parece estar a gusto. Ha pasado a ser, de un joven que dormía en soledad al pie de los árboles, a todo un licenciado trotamundos; puede ser que la manera en que lo haya hecho no nos convenza, pero el abrupto ascenso social no es de desdeñarse ${ }^{12}$. Hasta ahora, Tomás ha satisfecho sus necesidades y deseos. El conflicto dramático del texto vendrá a ser producto de la entrada de la "dama de todo rumbo y manejo" que se enamora de Tomás.

A Stanislav Zimic le parece absurdo "culpar a Tomás de «no comprender el amor», de transgredir contra la «armonía natural humana» y hasta de pecar contra «la ley divina del amor», por no corresponder «al gusto de la señora» que se apasiona de él"13; se trata, además, de una "dama de todo rumbo y manejo". Zimic tiene una buena idea aquí, pero para muestra no sirve este solo botón. Además, ¿cuál es el afán casamentero de ciertos críticos? El hecho de que Tomás se niegue a tener relaciones sexuales con una cortesana no revela inquietudes existenciales ni homosexualidades solapadas en él, sino el chovinismo de algunos de sus lectores. Es verdad que la boda es la consecuencia lógica de la gran mayoría de los textos literarios que tratan ciertos temas, pero el personaje que rechaza el amor no tiene que ser identificado, invariablemente, con un enfermo. Tomás no ha tenido la

${ }^{10}$ Sybil Dümchen, "The function of madness in El licenciado Vidriera", en Cervantes's exemplary novels and the adventure of writing, eds. M. Nerlich \& N. Spadaccini, The Prisma Institute, Minneapolis, 1989, p. 107.

11 Ibid., p. 110.

${ }^{12}$ JosEPH V. Ricapito entiende a Tomás como un trepador social y documenta la dificultad del ascenso (véase Cervantes's Novelas ejemplares: Between history and creativity, Purdue University Press, West Lafayette, 1996).

${ }^{13}$ S. Zimic, art. cit., p. 257. 
oportunidad de experimentar el amor en otros casos, llamémosles más justos, por estar imbuido en su meta principal: adquirir fama por su inteligencia. Hay que ubicar el rechazo al amor de parte de Tomás desde una perspectiva más justa.

La sabiduría que desea Tomás tiene un requisito: nuestro personaje debe estar apartado del contacto físico. Esta anomalía no es patológica necesariamente. El erotismo (vitalismo) de sus compañeros de clase también los ha imposibilitado; por eso, el licenciado tiene (o cree que tiene) que convertirse en un ermitaño-santo-loco asexuado. Para obtener lo que quiere, Tomás tiene (o entiende que tiene) que renunciar a la sexualidad. Como en el caso de Marcela, la sexualidad se convierte en una distracción de los objetivos principales del personaje. La necesidad de catalogar esto como "enfermizo" es una idea, casi muletilla postfreudiana, que nos aleja del verdadero entendimiento de la cultura de la época, todavía influenciada por el estilo de vida monástico.

En el rechazo de Tomás al amor -apunta María A. Cruz Cámara-se revela el temor de nuestro personaje a relacionarse, dado que esto implicaría una pérdida de su identidad ${ }^{14}$. La crítica entiende el temor (no el deseo) como motor de la acción: como Tomás teme, se aleja y recurre a los libros. Pero el punto de partida no debiera ser el temor sino el deseo ${ }^{15}$; este enfoque sería mucho más positivo y menos clínico: dado que Tomás recurre a los libros, se aleja del contacto físico. La desmesura del personaje provoca que una decisión excluya a la otra, pero esta desmesura no tiene por qué ser el aplacamiento de una desviación, parece más bien la característica notable de un personaje que merece ser narrado. Tomás es curioso, no enfermizo.

Ahora bien, habría que plantearse si el membrillo aleja o acerca a Tomás a su meta. Por mi parte opto por una respuesta inclusiva: de una forma lo aleja, pero de otra lo acerca. El membrillo no es un afrodisíaco efectivo en la novela; lo único que hace es envenenar a nuestro personaje, en este sentido, es un sexo metafórico, como señala Molho. No estoy de acuerdo, sin embargo, con la idea de que el trauma de Tomás se deba a que lo hayan forzado a comerse un sexo femenino metafórico, por la simple razón de que él lo come por voluntad propia. Curiosamente, además, en adelante el licenciado Vidriera subsistirá sólo de frutas. El veneno que dañó su cuerpo, y el reconocimiento de parte de Tomás de que lo comió por libre albedrío, causa la locura subsiguiente. Pero este conocimiento es el de un retruécano ${ }^{16}$. El

${ }^{14}$ Cf. María A. Cruz Cámara, "Cervantes como analista de la conducta humana: la inseguridad ontológica del protagonista de El licenciado Vidriera", Explicación de Textos Literarios, 1991-92, núm. 20, p. 17.

15 Véanse, S. Hutchinson, art. cit. y J. G. Weiger, op. cit.

${ }^{16}$ Otro extraño bálsamo cervantino, el de Fierabrás, funciona por medio de la sugestión del paciente. 
veneno ha puesto su cuerpo en un estado de ánimo susceptible de consideraciones extrañas:

Comió en tal mal punto Tomás el membrillo que al momento comenzó a herir de pie y de mano como si tuviera alferecía, y sin volver en sí estuvo muchas horas, al cabo de las cuales volvió como atontado, y dijo con lengua turbada y tartamuda que un membrillo que había comido le había muerto (p. 53).

El retruécano va a caracterizar el lenguaje y la mismísima locura de Vidriera ${ }^{17}$. La conexión entre el membrillo y la locura está en la paranomasia lingüística; el "ingenio" de Vidriera es, justamente, producto de su juego con las palabras. Así, el doble sentido de los términos de las expresiones irónicas lleva el argumento de éstas. Dicho de otro modo, el licenciado Vidriera no ve la diferencia que hay entre significado y significante ${ }^{18}$. Es importante notar que esto es, precisamente, lo que le granjea su fama. Por ejemplo, la gracia del chiste: "Esperad, Domingo, a que pase el Sábado" (p. 56), consiste en que alguien se llama Domingo, hay un judío asociado al sábado, y el sábado, en la semana, viene antes que el domingo.

Después de probar la fruta metafórica, el membrillo, nuestro personaje sólo comerá frutas. Estas frutas, además, han estado en contacto con el orín; en este sentido son una alusión al membrum. El membrillo es un sexo metafórico, de equívoco lingüístico, y las frutas, al estar en contacto con la "vasera de orinal", vienen a ser, también, sexos metafóricos.

Creo que la locura de Vidriera es, pues, producto de un reconocimiento irónico: luego de luchar contra las distracciones de la vida y la carne ha caído en las manos de lo que huía. Como esta caída ha sido metafórica (o más bien, lingüística), nuestro personaje adquiere una fijación con la paranomasia. La dedicación libresca del personaje se convertirá en una perversa fijación lingüística. El pecado de Tomás "no es el pecado de la carne, el mundo sensual frente al mundo del espíritu; es el pecado de la inteligencia"19. El rígido Tomás ha

17 Esta es una de las principales semejanzas entre la novela y los Sueños de Quevedo. El retruécano es lo que organiza el sistema penitenciario infernal en un texto, y la condena social (el chisme o la caída de la fama), en el otro. También hay un parentesco con Erasmo (S. DüMCHEN, art. cit., p. 100). Véase el estado de la cuestión en el ensayo de George Shipley, "Vidriera’s blather", Cervantes, 22 (2002), núm. 2, 49-124.

18 "A don Quijote le consideran loco cuantos le rodean por la absoluta integridad con que pone de acuerdo su pensamiento y su conducta. Al licenciado Vidriera, por la absoluta integridad con que pone de acuerdo su pensamiento y sus palabras" (LUIs Rosales, "La evasión del prójimo o el hombre de cristal", Cuadernos Hispánicos, 28.81, 1956, p. 257).

${ }^{19}$ Joaquín Casalduero, Sentido y forma de las "Novelas ejemplares", Gredos, Madrid, 1969, p. 148. 
sido laxo, ha permitido que se le envenenara (no ha tenido el conocimiento para evitarlo) y la anagnórisis ocasionada por el envenenamiento lo retrotrae al juego lingüístico que caracterizará su estado alterado de conciencia posterior. Dentro del contexto de los Sueños de Quevedo (y, en menor grado, El diablo cojuelo), esta propuesta no parece descabellada.

Además, los comentarios del licenciado Vidriera guardan similitud con las danzas macabras góticas, como señala Casalduero ${ }^{20}$. Tomás se obsesiona con la muerte y adquiere el vocabulario de ésta ${ }^{21}$ porque se le han truncado los sueños ${ }^{22}$. Hay una similitud entre el viaje a Italia y las descripciones quevedianas de los oficios y tipos que hace el licenciado loco: son revisiones panorámicas que elabora un personaje que quiere conocerlo todo, con la excepción del ángulo macabro postraumático. La diferencia entre la prisa del viaje y la de la procesión de oficios es el matiz macabro y el juego verbal: el personaje, que se presenta como un chapucero ante algunas lecturas (G. Shipley, por ejemplo ${ }^{23}$ ), es el mismo.

Por otro lado, la locura que produce el membrillo en Tomás lo acerca a su meta. Él no es "como los otros hombres" (p. 53), ahí está el núcleo de su locura. Ser de vidrio lo hace diferente, esa es la razón por la cual está hecho de vidrio ${ }^{24}$. Si bien es cierto que el vidrio es lo más opuesto a la carne -como sostiene Molho-, también obra "por ella el alma con más prontitud y eficacia, que no por la del cuerpo, por ser pesada y terrestre" 25 . El licenciado Vidriera es, en efecto, diferente, y esta diferencia (estar hecho de vidrio, aunque sea metáfora o locura) lo hace super-agudo ${ }^{26}$ y, más importante, lo acerca a su meta. La facilidad verbal le acarrea fama, Vidriera es lo que siempre quiso ser Tomás: un sabelotodo. Dicho de otra forma: la locura es la herramienta final que permitirá a Tomás realizar sus deseos.

${ }^{20} \mathrm{~J}$. Casalduero, op. cit., p. 140.

${ }^{21}$ Ibid., p. 148.

22 Véanse, J. G. Weiger, op. cit., J. Ricapito, op. cit. Casi todos los críticos tienen algo que comentar a este respecto: "El temor a la muerte no es por la destrucción del cuerpo, sino la pérdida de la identidad” (M. A. Cruz Cámara, art. cit., p. 19). También cita (p. 18) a A. J. Cascardi, quien concluye que el miedo a la muerte va unido a la evasión del prójimo.

${ }^{23}$ Véanse, de G. SHiPley, "Garbage in, garbage out: The best of Vidriera", Cervantes 21 (2001), núm. 1, 5-41 y "Vidriera's blather".

${ }^{24}$ Él no se queja por quejarse, o al menos no de lo que se lamenta el vulgo. Defiende, sí, a escribanos y frailes por el mero hecho de que son vituperados por la gente común. Vidriera es, ante todo, heterogéneo.

25 M. Molho, art. cit., p. 53.

${ }^{26} \mathrm{El}$ personaje era, por supuesto, inteligente desde un principio; como se ve, todo se relaciona con la manifestación de su inteligencia. Sin embargo, esa agudeza no será tal para críticos como JosEPH RICAPITO y GEORGE SHIPLEY (de este último, sobre todo, véanse "Vidriera's blather" y "Garbage in..."). 
Tomás había observado, con la consabida prisa, las distintas profesiones y tipos que encontraba por el camino; como Vidriera, tiene la oportunidad de poner en práctica, con juegos de palabras, los conocimientos que ha adquirido. Vidriera es el colmo del letrado, que no ve diferencia entre el rubí y los labios de los poetas (p. 60), entre la pinta de una barba y su color (p. 68), entre los títeres y lo que representan (p. 66); es una especie de fetichista de la palabra. Su locura (estar hecho de vidrio) pudiera ser producto de la fragilidad anímica entendida literalmente.

Ahora bien, la locura del licenciado Vidriera no es íntegra; en ciertos momentos el personaje sufre algunos quiebres, cuando la ocasión lo amerita. Por eso, una abeja puede picar su cuerpo de vidrio (p. 71); por eso, además, su memoria le permite acordarse de cuando era hombre de carne (pp. 61,63). Vidriera prefiere decir una agudeza a que su locura tenga consistencia; don Quijote, por otro lado, nunca rompe con la estructura de su personaje. Para Vidriera importa la agudeza, porque la agudeza acarrea fama.

Una vez recuperado, Tomás adopta el nombre de Rueda. La palabra "rueda" ha aparecido antes en el texto: "En la rueda de la mucha gente que, como se ha dicho, siempre le estaba oyendo..." (p. 64); "llegó al patio, donde le acabaron de circundar cuantos en él estaban. Él, viéndose con tanta turba a la redonda, alzó la voz" (pp. 73-74). La rueda y el círculo están vinculados con la fama de Vidriera ${ }^{27}$; Tomás ha llegado a ser famoso en la corte, a honrar a sus padres y a su patria usando su ingenio, como siempre quiso. Satisfecho, consumado, anhela lo más común del mundo: vivir de su profesión de sabelotodo. Saca, pues, a relucir sus títulos, hace una breve apología e invita a sus futuros clientes a pasar por su casa-oficina para ganarse la vida (p. 74). La conclusión no puede ser más desgarradora ni el final más irónico: a la gente no le interesa su conocimiento, su pericia verbal ni su ingenio, a menos que él se comporte como loco. Como excéntrico y bufón, Tomás tiene interés para el vulgo; como profesional, no ${ }^{28}$.

"No ganaba cosa y se moría de hambre" (p. 74). El final, que se apresura deliberadamente, es triste y sarcástico de manera simultánea. La ironía es que un intelectual no puede vivir de su ingenio en la corte, porque uno no puede tener lo que desea. El final, como casi todos los finales cervantinos, es problemático. Dümchen opta porque Tomás

\footnotetext{
${ }^{27}$ Hay, naturalmente, muchísimas interpretaciones posibles para esta polisémica palabra, una buena cantidad de ellas explotadas por la crítica. Tomás rueda en su desplazamiento, su locura es producto de la rueda de la fortuna, es rodaja antes y rueda después que completa su trayectoria... Aquí me sirvo de la que me resulta más útil.

28 ¿Por qué recobra Tomás la cordura? Quizás por la misma esquiva razón que don Quijote, un motivo que sobrepasa el asedio crítico. Por mi parte, opto por una causa formal; de este modo, la narración dibujaría un círculo. En última instancia, el asunto no importa demasiado, lo que interesa en la historia es el primer paso, que va de la cordura a la locura.
} 
"is not cured at all; he simply no longer believes that he is made of glass" 29 . Estoy más de acuerdo con Weiger, que ve en nuestro personaje "the result of the individual's own decision" ${ }^{30}$. El licenciado Vidriera quiere abarcar todo el conocimiento de manera inmediata, apresurada. Al respecto, Arlene Guerrero-Watanabe opina que "el protagonista no se vuelve loco por su lectura, sino porque su identidad, basada en el mundo intelectual... no basta para enfrentarse con... la experiencia humana" ${ }^{1}$. Puede que esto sea verdad, pero uno corre el riesgo de repetir los prejuicios de los contemporáneos de Vidriera. Aun en sus momentos más didácticos, Cervantes nunca deja de tener compasión por sus protagonistas.

Terminaré esta nota refiriéndome al personaje de Marcela. La crítica se ha contagiado del odio de los amigos de Grisóstomo (incluso los defensores de Marcela). Así pues, Ruth El Saffar piensa que la pastora vive "beyond the confines of the patriarchaly constructed world into which she was born" 32 . Mas allá, El Saffar sostiene -y esta me parece una idea mucho más interesante-que Marcela es incapaz de amar (aunque la estudiosa retrotraiga la causa a orígenes infantiles: la ausencia de la madre y demás lugares comunes psicoanalíticos) y que no es dura ni cruel, sino que simplemente se siente cómoda en su mundo artificial. Coincido con El Saffar en que, de casarse, "she would have to be the wealth and beauty attributed to her, in rejection of her own experience of herself" (p. 173) aunque no creo que esta sea una cuestión que concierna al texto. Más conciso y preciso, Carroll Johnson argumenta que Marcela de hecho experimenta deseo sexual, pero que escapa a un espacio de ficción (environment) para negar los impulsos que la fuerzan.

Ninguno de estos críticos - por lo demás, acertados- se pregunta detenidamente qué quiere Marcela. Indagan sobre las causas, los orígenes ocultos; examinan los medios, las desviaciones psíquicas de los procedimientos y planes de acción del personaje, pero no se preguntan qué quiere. El psicoanálisis a veces sufre la falla de obviar lo que anhela el sujeto. Como el paciente es un enfermo a priori, sus deseos no son pertinentes; lo que quiere (y, más aún, lo que dice querer) es secundario o incluso una mera excusa para muchos críticos en esta línea, por más rigurosos que sean.

${ }^{29}$ S. DÜMCHEN, art. cit., p. 114.

${ }^{30}$ J. G. Weiger, op. cit., p. 22.

31 Arlene Guerrero-Watanabe, "Melancolía narrativa. Estrategias y estructuras textuales en El licenciado Vidriera”, Cuaderno Internacional de Estudios Hispánicos y Lingüistica, 2002, núm. 2, p. 25.

32 R. El SAFFar, "In Marcela's case", en Quixotic desire: Psychoanalytic perspectives on Cervantes, eds. R. El Saffar \& D. de Armas Wilson, Cornell University Press, Ithaca, 1993, p. 159. Puede también verse, de esta misma autora, Critical essays on Cervantes, G. K. Hall, Boston, 1986. 
S. Hutchinson ha explicado cómo el deseo es una activación del alma que se manifiesta con un movimiento concreto ${ }^{33}$. Este movimiento tiende a ser un desplazamiento espacial, pero en el caso de las mujeres cervantinas se puede presentar como una afinidad con un espacio específico. Marcela encuentra lo que desea en el espacio que la inmoviliza. A Marcela no le interesa la sabiduría (o la fama) tanto como una vida de contemplación. Su "locura" sería recrear una fantasía pastoral; en este sentido, ella cambia de personalidad, lo mismo que Vidriera. El joven que se enamora de ella no es más que un estorbo pusilánime; Marcela lo rechaza con cierta misericordia, pero con fría decisión. De nuevo, aquí, el rechazo al amor es una forma de autoafirmación.

Así, traer a colación ideas sobre el coqueteo femenino afines a Freud, y concluir que Marcela seduce a los hombres que la observan mediante un narcisismo extremo, me parece un exceso de libertad interpretativa. Eso hacen, precisamente, Laura Garfkle y Amy Williamsen ${ }^{34}$. Marcela no es lo suficientemente femenina como para obrar de esa forma; habría que entender su deseo, más bien, como la sublimación del deseo en general mediante una alusión mística o, lo que parece más probable, la sublimación del deseo mediante la localización del objeto del deseo en el espacio de la naturaleza (lo que, al menos para los románticos, sería otra forma de misticismo ${ }^{35}$ ):

Si yo conservo mi limpieza con la compañía de los árboles, ¿por qué ha de querer que la pierda el que quiere que la tenga con los hombres? Yo, como sabéis, tengo riquezas propias y no codicio las ajenas; tengo libre condición y no gusto de sujetarme; ni quiero ni aborrezco a nadie. No engaño a éste, ni solicito aquél; ni burlo con uno, ni me entretengo con el otro. La conversación honesta de las zagalas destas aldeas y el cuidado de mis cabras me entretiene. Tienen mis deseos por término estas montañas, y si de aquí salen, es a contemplar la hermosura del cielo, pasos con que camina el alma a su morada primera (p. 198).

Hutchinson se detiene a analizar el uso de la fraseología que se refiere al deseo. Si analizamos el fragmento citado de esta manera, nos damos cuenta de que tanto la conversación de las zagalas como las cabras entretienen, mientras que el deseo se satisface con el espacio. El

33 S. Hutchinson, art. cit., p. 161.

34 Véanse, Laura Garfkle \& Amy Williamsen, "Mimetic desire and the narcissistic woman", $H, 77$ (1994), 11-23.

35 También, a su manera, para el hombre renacentista y barroco. De todas formas, en estas aguas profundas prefiero no meterme. Sí señalo, sin embargo, la presencia de "árboles" y "soledad" en un mismo contexto; esta coincidencia de objetos sería baladí si no fuera porque reaparece en las primeras líneas de El licenciado Vidriera. Es común asociar la soledad con los bosques (llenos de árboles), pero el árbol puede ser entendido, también, como una más definida metáfora del deseo ensimismado. 
deseo y el entretenimiento no son lo mismo (ni siquiera en el sentido que los términos tenían en el siglo XVII).

Marcela desea un espacio que se define, en parte, por la soledad. La soledad supone la ausencia de "entes deseantes": al convertir el espacio en objeto de deseo, la autocaracterización del ser como cosa deseada se contradice decisivamente. Es claro que Marcela quiere que la dejen tranquila, y tanto los hombres de su pueblo como algunos desorientados críticos insisten en casarla -suicidándose unos y especulando otros, al ver su negativa-, ninguno se sienta a escuchar al personaje.

Es posible que la estudiada cosificación del licenciado Vidriera tenga relación con la fantasía de Marcela: el enlace se manifiesta, principalmente, en la misantropía, entendiendo por ella el rechazo al amor y al contacto físico (que en el caso de Marcela se traduce en una más fuerte voluntad de soledad). Los cuerpos de los personajes, entonces, no se transforman en cuerpos "realistas", sino en vidrio, en un caso, o en una manifestación literaria en otro.

Alejandro Carpio Universidad de Puerto Rico 